\title{
MMW-ONLINE-SPRECHSTUNDE
}

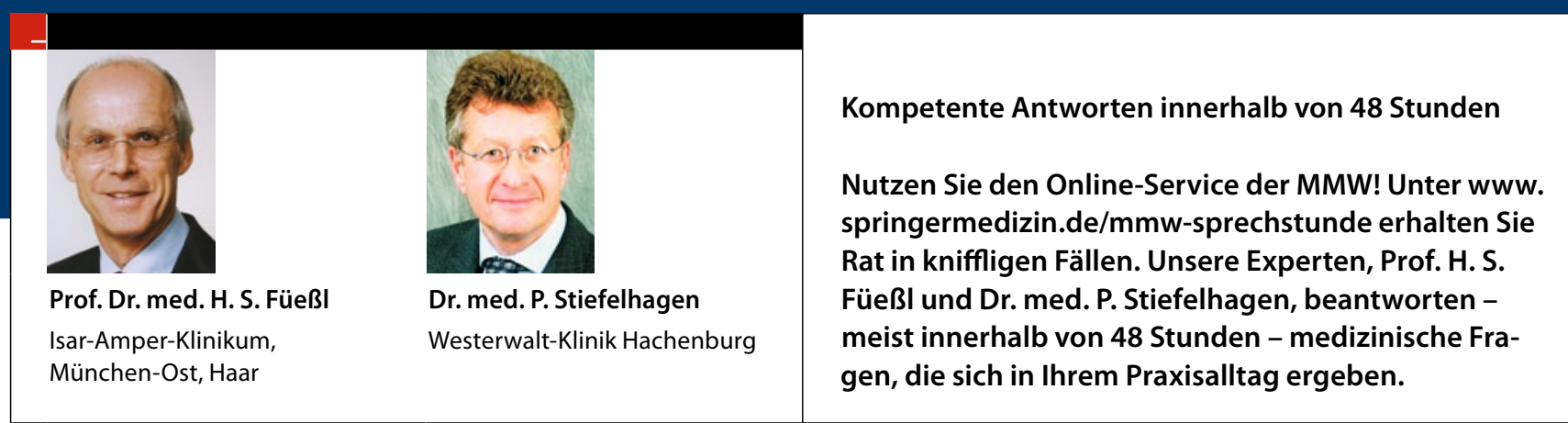

Mutter, Vater und Bruder sind an Malignomen gestorben

\section{Wie nehme ich meiner Patientin die Krebsangst?}

Frage von Dr. G. S.: Eine 60-jährige Patientin von mir hat Angst vor Krebs. Mutter und Vater sind an Krebs gestorben, der Bruder (schwerer Raucher) an Kehlkopfkrebs. Der Urologe hat nun Polypen in der Blase entdeckt. In der Klinik wurden sie entfernt, auf einer Skala von 1 bis 30 bekamen sie eine 2 (geringes Risiko). Die Patientin soll nun alle drei Monate zur Blasenspiegelung.

Die Patientin würde gern generelle Tests machen, „,ob da irgendwo Krebs ist “. Was kann ich ihr sagen, außer dass ihr Blutbild in Ordnung ist und keine Symptome vorliegen? Ich kann ihr ja auch nicht sagen, sie soll etwas rationaler sein.

MMW-Experte Dr. Stiefelhagen: Allgemeine Labortests zur Früherkennung eines okkulten Malignoms gibt es nicht. Die Bestimmung von Tumormarkern im Rahmen eines Screenings ist nicht sinnvoll, da sie angesichts der geringen Sensitivität und Spezifität keine ausreichende diagnostische Sicherheit bieten und zahlreiche falsch postive Befunde zu erwarten sind. Die einzige sinnvolle Früherkennungsmaßnahme ist die totale Koloskopie. Mehr gibt es nicht.

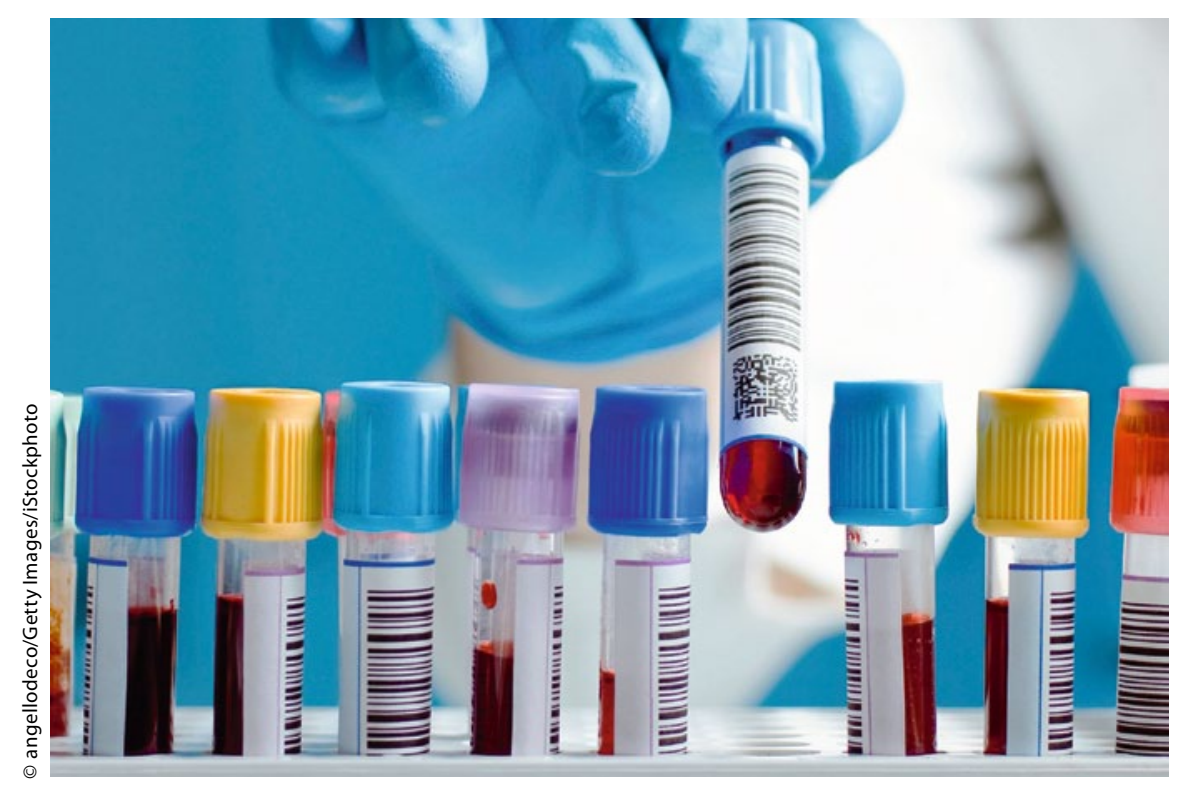

MMW-Experte Prof. Füeßl: Aufgrund der Familienanamnese liegt bei der Patientin zweifellos ein erhöhtes allgemeines Risiko vor, ebenfalls eine Krebserkrankung zu erleiden. Früherkennungsmaßnahmen über Blutuntersuchungen, zum Beispiel durch Untersuchung sog. Tumormarker, haben sich als Screening-Untersuchungen nicht bewährt. Dies vor allem, weil die Rate der falsch positiven Untersuchungsergebnisse viel zu hoch ist, als dass diese Untersuchungen vernünftigerweise empfohlen werden könnten. Die einzige Screening-Maßnahme, die nachweislich zu einer Senkung der Mortalität am kolorektalen Karzinom geführt hat, ist die Vorsorge-Koloskopie. Sie sollte daher bei allen Personen mit durchschnittlichem Risiko ab dem 55. Lebensjahr alle zehn Jahre einmal durchgeführt werden. Bei positiver Familienanamnese für ein kolorektales Karzinom empfiehlt sich eine erste Untersuchung bereits mit 45 Jahren.

Sowohl der Kehlkopfkrebs des Bruders als auch das bei der Patientin entdeckte Blasenkarzinom sind deutlich mit dem Zigarettenrauchen assoziiert. Ist die Patientin Raucherin? Die gestellte Diagnose wäre ein guter Einstieg, mit dem Rauchen aufzuhören. Im Übrigen könnte bei der Patientin eine allgemeine Angststörung vorliegen, die durch Bluttests ohnehin nicht zu verringern ist. Hier wäre eher an psychotherapeutische Maßnahmen zu denken.

Abb. 1 Zu oft falsch positiv: Bluttests auf Krebsmarker. 